\title{
GAMBARAN AKTIVITAS FISIK, STATUS GIZI DAN TEKANAN DARAH REMAJA BINAAN DINAS SOSIAL PALU TAHUN 2018
}

\author{
Melisa Abbas ${ }^{1}$, Mayalisa Diantamaela ${ }^{1 *}$, Nila Ardila Arif ${ }^{1}$ \\ ${ }^{1}$ Program Studi Pendidikan Dokter, Fakultas Kedokteran Universitas Alkhairat, Jl. Diponegoro No. 39 \\ Palu 94221, Sulawesi Tengah, Indonesia \\ "Corresponding author: Telp: +6285285619045, email: dr.mayalisabikusno@gmail.com
}

\begin{abstract}
ABSTRAK
Pola makan dan akivitas fisik yang tidak seimbang merupakan faktor penyebab obesitas dan hipertensi. Saat ini pola konsumsi gizi pada remaja lebih banyak ditentukan dari lingkungan pergaulan. Sementara aktivitas yang dilakukan sangat kurang, sehingga beresiko tinggi untuk memiliki status gizi lebih. Angka kejadian aktivitas fisik pada remaja di Indonesia yang kurang aktif masih cukup tinggi, begitupun tekanan darah tinggi dan obesitas di Sulawesi tengah juga masih cukup tinggi. Penelitian ini bertujuan untuk mengetahui gambaran aktivitas fisik, status gizi dan tekanan darah remaja binaan Dinas Sosial Palu tahun 2018. Metode penelitian adalah deskriptif terhadap 30 anak remaja binaan Dinas Sosial Palu 2018. Data diperoleh melalui pengisian kuesioner dan pemeriksaan yang diisi pada case report . Di lakukan analisis distribusi frekuensi menggunakan program SPSS 21. Hasil penelitian: (1) aktivitas fisik terbanyak yaitu tidak aktif (76,7 \%), kurang aktif (23,3\%), aktif (0,0 \%). (2) kategori status gizi yang terbanyak yaitu gizi normal $(56,7 \%)$, gizi kurang $(23,3 \%)$, gizi lebih $(20,0 \%)$, (3) kategori tekanan darah yang terbanyak normotensi $(93,3 \%)$, prehipertensi $(6,7 \%)$. Remaja binaan dinas sosial palu, sebagian besar berstatus gizi normal, tetapi mereka mempunyai aktivitas fisik yang rendah. Temuan gizi kurang masih cukup besar. Tidak ditemukan remaja yang obesitas maupun hipertensi.
\end{abstract}

Kata Kunci : Aktifitas fisik, Status gizi, Tekanan Darah

\begin{abstract}
Unbalanced diet and physical activity are factors that cause obesity and hypertension. Currently the pattern of nutritional consumption in adolescents is more determined by the social environment. While the activities carried out are very lacking, so there is a high risk of having more nutritional status. The incidence of physical activity in under-teens in Indonesia is still quite high, as well as high blood pressure and obesity in Central Sulawesi are also still quite high. This study aims to describe the physical activity, nutritional status and blood pressure of adolescents assisted by the Palu Social Service in 2018. The research method was descriptive of 30 adolescents assisted by the Palu Social Service 2018. Data was obtained through filling out questionnaires and examinations which were filled in case reports. The frequency distribution analysis was carried out using the SPSS 21 program. The results of the study: (1) the most physical activity was inactive (76.7\%), less active (23.3\%), active (0.0\%). (2) the most nutritional status categories were normal nutrition (56.7\%), malnutrition (23.3\%), over nutrition (20.0\%), (3) the most normotensive blood pressure category (93.3\%), prehypertension (6.7\%). Adolescents are guided by the hammer social service, most are normally nutritional status, but they have low physical activity. The findings of malnutrition are still quite large. There are no obese and hypertensive teens.
\end{abstract}

Keywords: Physical activity, nutritional status, blood pressure 


\section{PENDAHULUAN}

Aktifitas fisik merupakan gerakan fisik yang dilakukan oleh tubuh dan sistem penunjang lainnya yang memerlukan energi. Menurut WHO aktivitas fisik adalah suatu bentuk pergerakan yang dilakukan seharihari yang membutuhkan energi ${ }^{1,2}$.

Sebuah penelitian menyebutkan bahwa aktivitas fisik dapat menurunkan tekanan darah pada individu yang menderita hipertensi (tekanan darah tinggi). Olahraga secara teratur dapat menyerap atau menghilangkan endapan kolesterol pada pembuluh darah ${ }^{3}$.

Masalah gizi yang timbul pada remaja saat ini disebabkan karena ketidakseimbangan antara kebutuhan energi dan zat gizi yang diperoleh, oleh sebab itu banyak remaja yang mengalami obesitas karena aktivitas fisik yang jarang dilakukan. Aktivitas fisik juga berpengaruh terhadap tekanan darah remaja. Karena aktivitas fisik yang sering dapat menurunkan tekanan darah pada penderita hipertensi. Masalah ini bukan hanya menjadi tanggung jawab sendiri tetapi juga menjadi tanggung jawab orang tua, lingkungan, dan pihak-pihak yang bersangkutan lainnya, agar dapat menurunkan resiko yang mungkin saja terjadi kepada remaja. Adanya hubungan antara status gizi (dalam hal ini obesitas) dan tekanan darah (tekanan darah tinggi/hipertensi) ditemukan oleh Verma et al. yang menelilti siswa sekolah berusia 5-15 tahun di kota Punjab, India. Berdasarkan penelitian Khasanah (2016) menunjukkan bahwa ada hubungan aktivitas fisik dengan status gizi remaja dengan nilai $(\mathrm{p}=0,005)$ pada remaja putri di Pondok Pesantren Ta'mirul Islam Surakarta.

Kesehatan remaja binaan Dinas Sosial Palu perlu diperhatikan selama mereka berada didalam asrama, karena selain mengasah kemampuan dari para remaja, mereka juga perlu diberikan pengetahuan tentang kesehatan. Agar jika mereka kembali ke rumah masing-masing, mereka dapat memberikan pengalaman kepada remaja lainnya. Selain itu, karena kebanyakan remaja yang dibina datang dari keluarga yang ber ekonomi menengah kebawah yang jarang memperhatikan pentingnya kesehatan terutama pada remaja. Maka dari itu, peneliti ingin mengetahui bagaimana gambaran aktifitas fisik, status gizi dan tekanan darah remaja binaan dinas sosial palu tahun 2018 .

\section{METODOLOGI}

Penelitian ini menggunakan metode deskriptif observasional dengan design cross sectional. Dimana pengambilan data dilakukan hanya satu kali pada satu saat. Penelitian ini dilakukan pada bulan Mei sampai Juli 2018 di Asrama Panti Binaan Anak "Putra Terbaik" Dinas Sosial Palu. Desain penelitian ini adalah Cross sectional di mana data diambil secara prospektif dari para remaja binaan dinas sosial palu.

Sampel dalam penelitian ini adalah total sampling. Alasan mengambil total sampling karena jumlah populasi yang kurang dari 50 jadi seluruh populasi dijadikan sampel penelitian. Cara pengambilan sampel adalah consecutive sampling yang merupakan salah satu cara dari nonprobability sampling. Dengan cara consecutive, peneliti mengambil semua subjek yang memenuhi kriteria, sampai besar sampel terpenuhi.

Dilakukan sampel random untuk menentukan anak terpilih kemudian populasi terpilih dan mendapatkan calon subjek terpilih, dimana calon subjek terpilih dinilai kriteria inklusi dan eksklusi untuk 
menemukan subjek terpilih. Kriteria inklusi adalah anak binaan Dinsos kota palu Lakilaki dan perempuan dengan usia remaja 1224 tahun, disetujui oleh orang tua/wali ikut penelitian tanpa paksaan setelah mendapat penjelasan. Kriteria eksklusi adalah anak binaan dinsos palu yang tidak bisa berkomunikasi.

Pengambilan data dengan melakukan pengisian kuisioner (Pengisian kuisioner dilakukan oleh peneliti) kemudian disertai dengan melakukan pemeriksaan pengukuran tekanan darah dengan menggunakan spygnomanometer dan stetoskop. Data yang telah terkumpul akan dilakukan pengolahan secara analiti komparatif tidak berpasangan dengan mengunakan program SPSS 21.

Penelitian yang saya lakukan tidak mengandung masalah yang dapat melanggar etik penelitian, karena sebelum melakukan penelitian, peneliti menjelaskan secara lengkap tentang tujuan, cara penelitian yang akan dilakukan dan dimintakan persetujuan dari setiap sampel.

\section{HASIL DAN PEMBAHASAN}

Pengumpulan data diperoleh melalui kuesioner dan case report. Data yang diperoleh antara lain aktivitas fisik, status gizi, dan tekanan darah. Hasil pengumpulan data dapat dilihat pada tabel sebagai berikut:

Tabel 1. Distribusi Responden Berdasarkan Aktivitas Fisik

\begin{tabular}{lcc}
\hline $\begin{array}{l}\text { Aktivitas } \\
\text { Fisik }\end{array}$ & Frekuensi & $\begin{array}{c}\text { Persentase } \\
(\%)\end{array}$ \\
\hline Aktif & 0 & $0 \%$ \\
Kurang aktif & 7 & $23,3 \%$ \\
Tidak aktif & 23 & $76,7 \%$ \\
\hline Total & 30 & $100 \%$ \\
\hline
\end{tabular}

Tabel di atas memperlihatkan interpretasi aktivitas fisik remaja binaan yang

tidak aktif sebanyak 23 anak (76,7\%), kurang aktif sebanyak 7 anak (23,3\%), sedangkan yang aktif $0(0 \%)$.

Tabel 2. Distribusi Responden Berdasarkan Status Gizi

\begin{tabular}{lcc}
\hline Status gizi & Frekuensi & $\begin{array}{c}\text { Persentase } \\
(\%)\end{array}$ \\
\hline Gizi kurang & 7 & $23,3 \%$ \\
Gizi normal & 17 & $56,7 \%$ \\
Gizi lebih & 6 & $20,0 \%$ \\
Obesitas 1 & 0 & $0 \%$ \\
Obesitas 2 & 0 & $0 \%$ \\
\hline Total & 30 & $100 \%$ \\
\hline Tabel di & atas memperlihatkan \\
interpretasi status & gizi & yang dinilai \\
berdasarkan IMT remaja binaan, sebanyak 7 \\
anak (23,3\%) gizi kurang, 17 anak (56,7\%) \\
gizi normal, dan 6 anak (20,0\%) gizi lebih, \\
sedangkan untuk obesitas 1 dan 2 tidak \\
didapatkan (0\%).
\end{tabular}

Tabel 3. Distribusi Responden Berdasarkan Tekanan Darah

\begin{tabular}{lcc}
\hline $\begin{array}{l}\text { Tekanan } \\
\text { darah }\end{array}$ & Frekuensi & $\begin{array}{c}\text { Persentase } \\
(\%)\end{array}$ \\
\hline Hipotensi & 0 & $0 \%$ \\
Normotensi & 28 & $93,3 \%$ \\
$\begin{array}{l}\text { Prehipertensi } \\
\text { Hipertensi }\end{array}$ & 2 & $6,7 \%$ \\
derajat 1 & 0 & $0 \%$ \\
$\begin{array}{l}\text { Hipertensi } \\
\text { derajat 2 }\end{array}$ & $0 \%$ \\
\hline Total & 0 \\
\hline \multicolumn{2}{c}{ Tabel di atas } \\
interpretasi tekanan darah remaja binaan, dan \\
didapatkan sebanyak 28 anak $(93,3 \%)$ \\
normotensi, 2 anak (6,7\%) prehipertensi, dan \\
untuk hipotensi, hipertensi derajat 1 dan 2 \\
tidak didapatkan (0\%).
\end{tabular}




\section{Gambaran aktivitas fisik remaja binaan}

Didapatkan sebanyak 23 remaja $(76,7$

$\%$ ) yang tidak aktif. Hal ini terjadi sebab kegiatan yang sering dilakukan adalah aktivitas ringan seperti kegiatan belajar mengajar di asrama. Hal ini sejalan dengan penelitian yang dilakukan oleh Daimatul Khasanah pada tahun 2016 yang mendapatkan aktivitas ringan 70,4\%, aktivitas sedang $18,5 \%$, dan aktifitas berat $11,1 \%$. Berdasarkan hasil recall aktifitas fisik 7x24 jam, aktivitas fisik pada subjek penelitian sebagian besar masuk dalam kategori aktivitas ringan, hanya sedikit yang masuk dalam kategori aktivitas sedang dan berat. Hal ini disebabkan karena sebagian besar aktivitas yang dilakukan hanya aktivitas ringan seperti membaca buku, berjalan kaki ke sekolah, belajar. Durasi dan frekuensi aktivitas tersebut hanya sebentar antara 5-30 menit.

\section{Gambaran status gizi remaja binaan}

Sebanyak 17 remaja $(56,7 \%)$ dengan status gizi normal. Tetapi remaja dengan status gizi kurang juga masih cukup tinggi ( 23,3\%). Hal ini sejalan dengan penelitian yang dilakukan oleh Daimatul Khasanah pada tahun 2016 yang mendapatkan status gizi normal $74,1 \%$, status gizi overweight $20,3 \%$, dan status gizi obesitas 5,6\%. Karena para remaja binaan makannya diatur oleh pihak asrama dari pagi sampai malam dan yang status gizi overweight atau obesitas kebanyakan ada tambahan makan yang lainnya atau makannya tidak dibatasi setiap harinya dan yang status gizi kurang mungkin dikarenakan oleh asupan nutrisi yang kurang masuk ataupun diakibatkan kurang asupan zat gizi karena pola makan yang salah akibat pengaruh lingkungan pergaulan. Terpenuhinya kebutuhan zat gizi adalah hal yang sangat diperlukan untuk mencapai tingkat kesehatan yang optimal. Asupan zat- zat gizi yang seimbang dengan kebutuhan remaja akan membantu remaja mencapai pertumbuhan dan perkembangan yang optimal. Ketidakseimbangan asupan kebutuhan zat gizi dapat menimbulkan masalah gizi baik berupa masalah gizi lebih maupun gizi kurang.

\section{Gambaran tekanan darah remaja binaan}

Sebanyak 28 remaja $(93,3 \%)$ memiliki tekanan darah normal. Hal ini dapat disebabkan karena aktivitas yang mereka lakukan kebanyakan aktivitas yang ringan dengan pola makan yang teratur yang berarti gizi yang mereka peroleh seimbang. Namun hasil ini tidak sejalan dengan teori yang didapatkan dimana tekanan darah akan cenderung meningkat bila kurang beraktivitas.

\section{KESIMPULAN}

Kesimpulan penelitian ini adalah remaja binaan dinas sosial palu, aktivitas fisik terbanyak adalah tidak aktif yaitu sebanyak 76,7 \%. Hal ini karena kegiatan yang disediakan di panti binaan kebanyakan didalam ruangan, untuk kegiatan diluar ruangan seperti olahraga masih kurang. Demikian pula status gizi terbanyak adalah gizi normal, tetapi yang berstatus gizi kurang masih cukup banyak karena pengaruh pola makan yang salah. Remaja binaan dinas sosial palu, terutama yang berstatus gizi kurang, memerlukan asupan ekstra dan gizi seimbang. Hasil tekanan darah remaja binaan dinas sosial palu adalah normotensi.

\section{DAFTAR PUSTAKA}

1. Alricson, M. Physical Activity Why and How?. Departement of Health Science. 2013.

2. Khasanah D. Hubungan aktivitas fisik dengan status gizi remaja di pondok 
MEDIKA ALKHAIRAAT : JURNAL PENELITIAN KEDOKTERAN DAN KESEHATAN 1(1): 12-16

e-ISSN: 2656-7822

pesantren Ta'mirul Islam Surakarta.

Skripsi. Surakarta. 2016.

3. Pickering Tet al. Recommendations for

blood pressure measurement in humans

and experimental animals. Part 1: blood

pressure measurement in humans.

Hypertension 2005; 45: 142-161. 2005. 